\title{
A formação sócio-espacial como categoria de análise aos estudos sobre rede urbana: ampliando a discussão teórica
}

\author{
José Messias Bastos* \\ Carlos Cassemiro Casaril $^{* *}$
}

\section{Resumo}

O presente artigo tem por objetivo ampliar a discussão e dar subsídios para a realização de análise de uma determinada rede urbana sob o paradigma da Geografia Crítica, mais precisamente, com o emprego da Formação Sócio-Espacial proposta por Santos (1977), derivada da Formação Econômica e Social proposta por Marx. Uma ressalva a ser feita é que a Formação Sócio-Espacial foi estruturada, tendo em vista um entendimento da totalidade espacial em macro escala (escala nacional), todavia a mesma não é percebida como um paradigma teórico-metodológico concretizado. Como exemplo, citamos o professor Armen Mamigonian e outros intelectuais discípulos seus, os quais comungam de uma mesma perspectiva teórica, sendo que para estes intelectuais a Formação Sócio-Espacial é e pode ser utilizada para analisar tanto a escala nacional como a regional.

Palavras-chave: Redes urbanas; Escalas geográficas; Formação sócio-espacial.

* Professor do Departamento de Geociências e do PPGG - CFH/UFSC (jbastos@cfh.ufsc.br).

** Doutor em Geografia pela UFSC (carloscasaril@yahoo.com.br).

Geosul, Florianópolis, v. 31, n. 62, p 271-298, jul./ago. 2016 
BASTOS, J.M. \& CASARIL, C. Formação sócio-espacial como categoria...

The socio-spatial formation as category of analysis to studies about urban network: broadening the theoretical discussion

\section{Abstract}

The present article has for objective broaden the discussion and give subsidies for the carry out analysis of a given urban network under the paradigm of Critical Geography, more precisely, with employment of the Socio-spatial Formation proposed by SANTOS (1977), derived from Economic Formation and Social proposed by Marx. One caveat to be made is that the socio-spatial Formation was structured with a view to an understanding of the spatial totality in macro scale (national scale), however, do not perceive it as a theoretical-methodological paradigm realized. As an example, we cite the professor Armen Mamigonian and other intellectual disciples his, which commune of the same theoretical perspective and for these intellectuals the socio-spatial Formation is and can be utilized to analyze both the nationally scale and regional.

Key words: Urban networks; Geographical scales; Socio-spatial formation.

\section{Introdução}

A Marx e Engels que lançaram a semente da Formação Econômica e Social.

A Lênin que a sistematizou e, brilhantemente nos mostrou que para lançarmos mão da Formação Econômica e Social teríamos que analisar uma sociedade espacialmente e temporalmente determinada, ou seja, incluiu o "espaço" em nossas análises.

A Milton Santos que através da brilhante categoria de Formação Econômica e Social uniu o espaço (que já estava unido, como Lênin nos mostrou, pois não existe a possibilidade de analisarmos uma sociedade a-espacial) e em $1977 \mathrm{fez}$ germinar a Formação Sócio-Espacial. 
BASTOS, J.M. \& CASARIL, C. Formação sócio-espacial como categoria...

O processo de urbanização enfrentado por muitos países na primeira metade do século XX originou reflexões de muitos analistas, visando, principalmente entender as problemáticas e a intensidade das transformações, sugerindo assim, soluções adequadas. As propostas de Walter Christaller (Central Places in Southern Germany, 1966), August Lösch (The economics of location, 1954), François Perroux ( $O$ conceito de pólo de crescimento, 1978), tornaram-se manuais importantes na literatura sobre as cidades estruturadas em redes, porque buscavam assinalar lógicas de organização espacial e apontar as relações decorrentes da ampliação da urbanização em uma dada região.

No Brasil, alguns pesquisadores comungaram desse tipo de análise, como os próprios analistas do Instituto Brasileiro de Geografia e Estatística (IBGE) e pioneiros nos estudos Pierre Deffontaines, Pierre Monbeig (1952, 1954) e Pedro Pinchas Geiger (1963), os quais analisaram a gênese e a evolução da rede urbana delineada entre as décadas de 1940 e 1960.

A inserção dos estudos sobre rede urbana no Brasil tem sua gênese a partir da publicação do artigo de Deffontaines (1944) "Como se constituiu no Brasil a rede das cidades", no Boletim Geográfico (publicação do Conselho Nacional de Geografia CNG - através do IBGE). Neste artigo, Deffontaines (1944, p.141) inicia sua discussão com algumas questões relevantes, dentre elas: "[...] como uma região foi dotada de aglomerações urbanas? Como nasceram elas, onde se instalaram, por que progrediram? Como se cria uma rede urbana? [...]". Tais questionamentos estão relacionados ao surgimento e a evolução de centros urbanos em uma determinada região e, consequentemente, com a estruturação de suas respectivas redes, indicando, em sua evolução histórica e geográfica, a possibilidade de reconhecimento de diversos momentos, reveladores dos processos de mudança sócio-espacial.

Deffontaines $(1944 ; 1945)$ assinala o estado da arte do sistema urbano brasileiro na década de 1930, assegurando que a rede urbana brasileira se encontrava em sua "infância", marcada pela expectativa de crescimento e instabilidade das cidades. 
BASTOS, J.M. \& CASARIL, C. Formação sócio-espacial como categoria...

$\mathrm{O}$ autor se diz espantado com a instabilidade da vasta quantidade de pequenas aglomerações do Brasil. Os centros urbanos não têm a fixidez das velhas cidades europeias:

[...] muitas são cidades em eclipse, e o número de cidades mortas é inteiramente anormal para um país novo, no qual a forma de cidade não tem três séculos de existência. A maioria das cidades mineiras está hoje em plena letargia, os pequenos portos da costa, muitas cidades de estrada ou cidades de rio estão também golpeadas mortalmente (DEFFONTAINES, 1945, p.306).

A respeito da configuração da rede de cidades no Brasil dos anos 1930-1940, Deffontaines sugere que

O Brasil não atingiu um estágio em que a divisão do trabalho tenha feito progressivamente descobrir as aptidões regionais variadas comportando interdependências e, portanto, do potencial urbano, as divisões naturais ainda não nasceram, uma monótona economia fechada continua espelhada muito generalizadamente, a noção de 'região', isto é, de paisagem que o homem confeccionou progressivamente pelas especializações de regime e de horizonte de trabalho, está ainda confusa [...] (DEFFONTAINES, 1945, p.307).

As análises do autor supracitado demonstram que a rede urbana nacional configura-se em uma formação desagregada em pequenos núcleos e não em um sistema urbano articulado. Deste modo, o autor apontava que essa era "[...] a característica de uma rede urbana na infância [...]" (DEFFONTAINES, 1945, p.308). Já outros pesquisadores em estudos posteriores mencionam não haver uma rede de cidades no Brasil naquele momento, pois o conceito de rede urbana se refere a um conjunto de cidades espacial e funcionalmente articulado. Concordamos com o conceito de rede urbana, igualmente com o assinalado por Deffontaines, que apontou que a rede de cidades estava em formação. 
BASTOS, J.M. \& CASARIL, C. Formação sócio-espacial como categoria...

Em 1956, durante o Congresso da União Geográfica Internacional (UGI), realizado no Rio de Janeiro, a temática da rede urbana aparece novamente e, a partir de então, vários pesquisadores realizaram análises sobre o tema. Durante a UGI um dos debates se deu em torno do papel das cidades, enquanto sustentáculos "[...] à atividade regional de produção industrial [...]", determinados conforme as atividades e as relações entre as cidades e seu entorno, assinalando, uma classificação estrutural e funcional dos centros urbanos (ROCHEFORT, 1959, p.427).

As excursões, previstas dentre as atividades do Congresso da UGI de 1956, resultaram na confecção de guias, produzidos com uma abordagem da Geografia clássica, material importantíssimo para o congresso, tanto que, tais guias foram mais difundidos do que as próprias comunicações do evento. Essas excursões (não analisaram somente os centros urbanos) procuraram apresentar os conjuntos regionais do Brasil, sobretudo para os estrangeiros. Nestes se percebe a tentativa de analisar a totalidade do conjunto regional nacional, como exemplo, se verifica que existiram excursões para a Serra da Mantiqueira e Região Sul de São Paulo; a Marcha do Café e as Frentes Pioneiras; Região Açucareira do Estado do Rio de Janeiro; a Região Metalúrgica de Minas Gerais e o Vale do Rio Doce; o Vale do Paraíba; o Planalto CentroOcidental e o Pantanal do Mato-Grosso; a Amazônia; a Bahia; o Nordeste e o Planalto Meridional (UGI, 1959).

Os anos seguintes ao Congresso foram marcados pelo fortalecimento do intercâmbio entre geógrafos franceses e brasileiros, parceria promovida desde a fundação da USP Universidade de São Paulo e da UDF - Universidade do Distrito Federal (atual UFRJ), que envolveram profissionais do nível de Pierre Deffontaines, Pierre Monbeig, Roger Bastide, etc. $\mathrm{Na}$ sequência destacaram-se o intercâmbio entre, principalmente Michel Rochefort e Pierre George.

Vale sublinhar que Rochefort, orientou o Grupo de Trabalho de Geografia Urbana do Departamento de Geografia do CNG, que resultou no trabalho, "O Rio de Janeiro e sua região", coordenado 
BASTOS, J.M. \& CASARIL, C. Formação sócio-espacial como categoria...

por Lysia Bernardes (1964); além do método de classificação das redes urbanas, de grande estima para o trabalho "Evolução da rede urbana brasileira" de Pedro Geiger (1963); somadas às publicações editadas pelo CNG, sobretudo, o "Esboço preliminar de divisão do Brasil em espaços homogêneos e espaços polarizados" (IBGE, 1967), e as publicações do IBGE, destaque para os "Subsídios à regionalização" (IBGE, 1968). Assim, percebemos que durante a UGI de 1956 e no decorrer dos anos 1960 os estudos urbanos marcaram intensa presença no Brasil.

As pesquisas desenvolvidas sobre a temática da rede urbana diminuíram durante um período, dando lugar para pesquisas em outras áreas contempladas pela geografia e voltaram a receber maior dedicação, a partir da década de 1990. Pode-se dizer que, até mesmo, durante toda a primeira década do século XXI, foram levados adiante estudos sobre a temática que ainda procedem da "teoria das localidades centrais" proposta pelo geógrafo Alemão Walter Christaller (publicado em língua alemã em 1933 e em língua inglesa em 1966), como a mais adequada teoria para problematizar uma dada rede urbana, ganham destaque, por exemplo, os estudos do IBGE, 2008; do Instituto Paranaense de Desenvolvimento Econômico e Social (IPARDES, 2004); e do Instituto de Pesquisas Econômicas Aplicadas (IPEA, 2002).

Este artigo além de referendar a teoria de Chrislatter (1966) como a mais adequada, traz como objetivo a proposta de ampliar a discussão e dar subsídios para a realização de análise de uma dada rede urbana sob o paradigma da Geografia Crítica, mais precisamente, com o emprego da Formação Sócio-Espacial (FSE) ${ }^{1}$, para tanto, utilizou-se como procedimento metodológico, uma revisão teórica e documental, a fim de entender o processo em pauta. Vale destacar que a formação sócio-espacial foi proposta por Santos (1977), e derivou da Formação Econômico-Social de Marx.

1 Vale destacar que, alguns autores já propuseram esta análise, como BESSA (2007), FERREIRA (2011), entre outros. Este trabalho busca ampliar a discussão da temática). 
BASTOS, J.M. \& CASARIL, C. Formação sócio-espacial como categoria...

Assim, comungamos de uma perspectiva teórica que vem sendo há muito negligenciada por vários geógrafos brasileiros.

Uma ressalva a ser feita neste momento é que a formação sócio-espacial proposta por Santos (1977) foi estruturada tendo em vista um entendimento da totalidade espacial em macro escala (escala nacional), todavia, não a percebemos como um paradigma teórico-metodológico concretizado. Como exemplo, podemos mencionar o professor Armen Mamigonian e outros intelectuais, discípulos seus, os quais comungam de uma mesma perspectiva teórica, que a FSE é e pode ser utilizada para analisar tanto a escala geográfica nacional, como a regional e a local.

Assim, este artigo esta dividido em duas partes, na primeira apresenta-se o paradigma da formação sócio-espacial, na segunda discute-se a FSE como teoria e como método aos estudos sobre a rede urbana (regional), além das considerações finais.

\section{O paradigma de formação sócio-espacial e seu uso nas análises de rede urbana}

Para o professor Armen Mamigonian o artigo "Sociedade e Espaço - a Formação Social como Teoria e como Método", publicado em 1977, tanto no Boletim Paulista de Geografia n.54, como na Antipode n.1, é “[...] o mais importante texto teórico de Milton Santos [...]" e "[...] constitui o marco fundamental da renovação da geografia humana atual” (1996, p. 198).

A categoria de Formação Econômica e Social (FES) teve sua conceituação inicial elaborada por Marx e Engels e sistematizada por Lênin, buscando compreender a totalidade da história e o desenvolvimento de uma sociedade. Segundo Santos (1977), Marx conseguiu fundamentar o método científico da FES, porque soube retirar desde o início os entendimentos histórico-filosóficos da sociedade em geral apresentando apenas uma análise científica de uma sociedade e de um progresso (CASARIL, 2008; 2014).

O entendimento da FES como parte de um processo histórico é dada por Marx (1983, p. 13) no prefácio de O Capital, 
BASTOS, J.M. \& CASARIL, C. Formação sócio-espacial como categoria...

quando entende "[...] o desenvolvimento da formação econômica da sociedade como um processo histórico-natural [...]". Assim partir disso, o desenvolvimento histórico e suas etapas se tornam o lugar central na interpretação das sociedades. Com isso, Marx buscava evitar o materialismo abstrato das ciências naturais, na qual o desenvolvimento histórico não é considerado. Portanto, o conceito da FES se refere a uma sociedade determinada, como Lênin fez a respeito do capitalismo da Rússia. "Assim é que a noção adquire o status de formações históricas e geograficamente localizadas, isto é, formações sócio-espaciais" (ESPÍNDOLA; SILVA, 1997, p. 61-62).

Milton Santos resgata a categoria marxista da FES, afirmando ser "[...] a mais adequada para auxiliar a formação de uma teoria válida do espaço. [...]" (SANTOS, 1977, p. 81). Como a produção é o elemento estruturante da FES, Santos (1977, p.82) argumenta que devido as transformações ocorridas no espaço acontecerem via trabalho, é impossível "[...] falar de Formação Econômica e Social sem incluir a categoria do espaço. [...]” Daí, a gênese do conceito de Formação Sócio-Espacial (FSE).

A FES ou simplesmente formação social (axial ao materialismo histórico) expressa "La unidad (y nosotros añadiremos por nuestra parte la totalidad) de las diversas esferas económica, social, política, cultural de la vida de una sociedad, y La expresa, [...] al mismo tiempo en la descontinuidad de su desarollo histórico" (SERENI, 1971, p.24).

A FSE refere-se à análise da concreticidade de uma sociedade (compreendendo sua evolução, sua situação atual, sua mudança histórica e suas relações) sendo esta uma realidade histórico-concreta, geograficamente localizada. $\mathrm{O}$ alicerce da explicação é a produção, onde o homem transforma o espaço. Seu estudo possibilita "[...] a apreensão do particular como uma cisão do todo, um momento do todo, assim como o todo reproduzido numa de suas frações. [...] mas sempre um conhecimento específico, apreendido num dado momento de sua evolução" (SANTOS, 1977, p.84). Assim, o primeiro passo para entender a 
BASTOS, J.M. \& CASARIL, C. Formação sócio-espacial como categoria...

FSE de uma dada rede urbana seria atingir a realidade (CASARIL, 2008; 2014).

"[...] A realidade é a unidade do fenômeno e da essência [...]" (KOSIK, 1976, p.12). Assim, chegar-se-ia a realidade, a partir da compreensão dos fenômenos e suas manifestações, sendo que, o entendimento do fenômeno permitir-se-ia atingir a essência e, através do fenômeno e da essência entra-se em contato com a realidade, ou melhor, com o mundo da concreticidade, rompendo com o mundo da pseudoconcreticidade (aparência).

O mundo da pseudoconcreticidade é um claro-escuro de verdade e engano. $\mathrm{O}$ seu elemento próprio é o duplo sentido. $\mathrm{O}$ fenômeno indica a essência e, ao mesmo tempo, a esconde. A essência se manifesta no fenômeno, mas só de modo inadequado, parcial, ou apenas sob certos ângulos e aspectos. $\mathrm{O}$ fenômeno indica algo que não é ele mesmo e vive apenas graças a seu contrário. [...] A essência se manifesta no fenômeno. [...] A manifestação da essência é precisamente a atividade do fenômeno (KOSIK, 1976, p.11).

Destruir a pseudoconcreticidade visando atingir a concreticidade "[...] é ao mesmo tempo um processo no curso do qual sob o mundo das aparências se desvenda o mundo do real [...]" (KOSIK, 1976, p.16). E para romper a aparência e desvendar o mundo real, ou seja, a totalidade é necessário entender a "[...] realidade como um todo estruturado, dialético, no qual ou do qual um fato qualquer (classe de fatos, conjunto de fatos) pode vir a ser racionalmente compreendido". Assim, a totalidade não é o conhecimento resultante da soma das partes. "Os fatos são conhecimentos da realidade se são compreendidos como fatos de um todo dialético [...] se são entendidos como partes estruturais do todo" (KOSIK, 1976, p.35-36).

A partir de uma proposta de trabalho que se utilize dessa categoria de análise, “[...] a totalidade concreta - para apreender a realidade, é um momento dado que se apreende, pois o todo está sempre se desfazendo e se refazendo para se tornar outro todo no 
BASTOS, J.M. \& CASARIL, C. Formação sócio-espacial como categoria... contínuo processo de desenvolvimento [...]" (FRESCA, 2000, p.12). Assim, só apreendemos a totalidade em um determinado momento, pois quando aquele momento foi apreendido já não será mais aquela totalidade, pois a mesma já se tornou outra.

O concreto é para o pensamento um processo de síntese e não um ponto de partida, apesar de ser o ponto de partida (MARX, 1987).

[...] O concreto é concreto porque é a síntese de muitas determinações, isto é, unidade do diverso. Por isso o concreto aparece no pensamento como processo de síntese, como resultado, não como ponto de partida efetiva e, portanto, o ponto de partida também da intuição e da representação. No primeiro método, a representação plena volatiza-se em determinações abstratas, no segundo, as determinações abstratas conduzem à reprodução do concreto por meio do pensamento [...] o método que consiste em elevar-se do abstrato ao concreto não é senão a maneira de proceder do pensamento para se apropriar do concreto, para reproduzi-lo como concreto pensado (MARX, 1987, p.17).

Assim, para se conhecer o contexto da realidade devemos separar " $[. .$.$] os fatos do contexto, isolando-os e tornando-os$ relativamente independentes. Eis aqui o fundamento de todo conhecimento: a cisão do todo. [...]" (KOSIK, 1976, p. 48). Assim, todo conhecimento é uma oscilação dialética e, como o objetivo da ciência é esclarecer a essência das coisas e não apenas descrever aparências, deve-se partir do fenômeno para alcançar a realidade que se oculta atrás do fenômeno, para tanto, o núcleo mediador é o método de investigação (CASARIL, 2008; 2014).

Assim, temos o materialismo dialético de conhecimento da realidade, o qual possibilita a passagem do abstrato ao concreto e o movimento de passagem da parte para o todo e do todo para a parte, ou seja, permite "[...] compreender a parte enquanto manifestação do todo. $\mathrm{O}$ todo pelo todo não existe, a não ser como mera abstração, porque é na parte que o todo se manifesta, se 
BASTOS, J.M. \& CASARIL, C. Formação sócio-espacial como categoria...

realiza" (FRESCA, 2000, p. 12-13). Portanto, para analisar a formação sócio-espacial de uma dada rede urbana tem-se que explorá-la como a parte do todo.

Santos (1977, p. 91), discutindo espaço e totalidade, assevera que as formações sociais influenciam os períodos posteriores dos modos de produção. Pois, “[...] o espaço reproduz a totalidade social [...] o espaço reproduz-se, ele mesmo, no interior da totalidade, quando evolui em função do modo de produção e de seus momentos sucessivos. [...]". E, além de influenciar os períodos subsequentes ao modo de produção, "[...] influencia também a evolução de outras estruturas e, por isto, torna-se um componente fundamental da totalidade social e de seus movimentos".

A esse respeito, o autor supracitado observa que, "[...] a unidade da continuidade e da descontinuidade do processo histórico não pode ser realizada senão no espaço e pelo espaço. [...]". Deste modo, "[...] A evolução da formação social está condicionada pela organização do espaço, isto é, pelos dados que dependem diretamente da formação social atual, mas também das formações econômico-sociais permanentes" Santos (1977, p. 90).

As formações sócio-espaciais, como etapas de um processo histórico, fazem referência ao desenvolvimento desigual das sociedades, o que, por sua vez, desvelam dados basilares para esclarecer por que países, regiões e por que não cidades diferenciam-se uns dos outros. O que, todavia, quer dizer que a base da organização/transformação espacial coexiste no embate entre o que está posto e o que se estabelece como novo, resultando em um espaço desigual e combinado (SANTOS, 1985).

Para o estudo de uma dada rede urbana, o conceito de FSE é singular, pois reside no fato deste ser indissociável do concreto, ou seja, a FSE faz referência como já mencionamos, a uma sociedade historicamente determinada, o que nos permite conhecer uma sociedade em sua totalidade e em suas frações, porém sempre um conhecimento particular, compreendido num determinado momento de sua evolução (SANTOS, 1977). 
BASTOS, J.M. \& CASARIL, C. Formação sócio-espacial como categoria...

Assim, a questão regional no Brasil pode ser determinada e apreendida tendo a FSE como categoria de análise basilar. Esta categoria permite compreender as relações de produção e forças produtivas, em suas desiguais celeridades no processo de acumulação capitalista, que contrapõem as áreas de pequena produção mercantil e de latifúndio, sendo que, estas duas formações representam, as totalidades sócio espaciais.

Estas duas formações genéticas, com suas dinâmicas econômico-sociais próprias, recebem importância significativa na literatura sobre as redes de cidades no Brasil.

Um dos autores, entre outros, a dar ênfase a esta importância é Corrêa (2006, p. 284-285) quando menciona dois aspectos, onde o primeiro consiste na "[...] drenagem da renda fundiária rural pela cidade, a partir do absenteísmo dos grandes proprietários [...]", uma particularidade das formações sócio-espaciais referendadas na grande propriedade; e o segundo aspecto é dado por uma "[...] distribuição mais equitativa da demanda e do consumo [...]" marcando " $[\ldots]$ uma mais nítida hierarquia de centros $[\ldots]$ " particularidade da FSE da pequena produção mercantil.

Deste modo, verifica-se que a partir destas duas formações sócio-espaciais apresentadas podem-se desenvolver análises sobre determinadas redes urbanas regionais. Assim, na sequência deste artigo discute-se a formação sócio-espacial como teoria e como método aos estudos sobre redes urbanas.

\section{A formação sócio-espacial como teoria e como método aos estudos sobre rede urbana: uma discussão necessária}

Os estudos sobre redes urbanas têm se constituído em um importante campo de pesquisa na geografia brasileira, desde meados dos anos de 1940, quando da introdução do tema no país através do artigo de Deffontaines $(1944 ; 1945)$ e, durante o Congresso da UGI, em 1956, se volta a discutir a temática.

Desde sua introdução até os dias atuais o tema passou por diversas fases de difusão e/ou realinhamento dos estudos e de 
BASTOS, J.M. \& CASARIL, C. Formação sócio-espacial como categoria...

confrontações do ponto de vista teórico-metodológico. Tais avanços podem ser entendidos a partir da vasta bibliografia com destaques aos trabalhos de Deffontaines (1944; 1945 [publicado originalmente em 1938 na França]); Monbeig (1943); Rochefort (1961); Geiger (1963); Bernardes (1964); Corrêa (1967; 1988; 1989; 1997), Müller (1969); Santos (1979; 1993); Fresca (1990; 2000); IBGE (1972; 1987; 2000; 2008); IPEA (2002); IPARDES (2002); Bessa (2007) etc., nos quais se realizaram avaliações da produção geográfica sobre redes urbanas no Brasil, bem como se produziram proposições teóricas e metodológicas para tais estudos.

Recentemente, a temática ganha evidência novamente, basta observarmos as recentes publicações, teses e dissertações defendidas na academia e a realização de eventos nos quais as discussões sobre as redes urbanas e outras redes geográficas proliferam. Essa proeminência encontra motivos no fato de que as transformações sócio-espaciais determinaram novos complicadores para as análises perante a atual fase do processo histórico de desenvolvimento do capitalismo, onde questões como mundialização do capital, neoliberalismo, imperialismo entre outras, estão presentes e, se legitimam na crescente concentração e centralização do capital.

A rede urbana constitui-se em um "[...] conjunto de centros funcionalmente articulados", o que por sua vez, reflete e condiciona as transformações econômico-sociais (CORRÊA, 1989, p.8). O importante é compreender que para desvelar uma dada rede urbana, a análise de sua gênese e dinâmica se torna imprescindível e, deve ser buscada em seu processo histórico, atribuindo a rede uma natureza social, tornando-a uma dimensão sócio-espacial, que reflete e condiciona a sociedade que a produziu. Deste modo, a rede urbana seria "[...] um produto social, historicamente contextualizado, cujo papel crucial é o de, através de interações sociais espacializadas, articular toda a sociedade numa dada porção do espaço, garantindo a sua existência e reprodução" (CORRÊA, 1997, p.93).

Sendo a rede urbana uma dimensão sócio-espacial da sociedade, constata-se que os processos de concepção, apropriação 
BASTOS, J.M. \& CASARIL, C. Formação sócio-espacial como categoria...

e circulação do valor excedente, estão igualmente em constante alteração. $\mathrm{O}$ que, todavia nos faz entender que a "[...] rede urbana constitui-se simultaneamente em um reflexo da e uma condição para a divisão territorial do trabalho" (CORRÊA, 1989, p.48).

É reflexo, pois a partir de centralidades e benefícios locacionais diferenciados, estruturam-se uma hierarquia urbana, promulgadora, por exemplo, de cidades comerciais, industriais, político-administrativas, portuárias, dentre outras.

A rede urbana é ainda condição para a divisão territorial do trabalho (DTT), pois define os pontos de relações e as vias de tráfego por onde os fluxos são postos e permitem a concepção e transformação constante e desigual de atividades e cidades (FRESCA, 2004). Assim, a rede urbana é condição para a DTT, pois através dos papéis de seus centros urbanos, articulam: setor primário, secundário, financeiro, comércio atacadista e varejista, serviços de armazenagem, transporte, administrativo, educação, saúde dentre outros. Portanto, são nos centros urbanos inseridos em uma determinada rede urbana, que se produzem as condições imperativas para a produção, distribuição, circulação e consumo.

Para Ribeiro (1998, p.63), a rede urbana sob o capitalismo representa "uma estratégia logística na acumulação de capital, que tem como expressão as cidades, dotadas continuamente de meios técnicos científicos, entre eles [...] um sistema de comunicação [...] e meios de transportes [...] que permitem a expansão do mercado".

Aqui é importante destacar novamente que, a rede urbana é dinâmica e mutável. Ela é nada mais que uma dimensão sócioespacial da sociedade, por isso passa a alterar-se conforme as transformações da sociedade. Se a totalidade da mudança institui uma nova organização espacial, por sua vez, a rede, como uma destas dimensões, passará por mudanças para dar conta das alterações da sociedade (SANTOS, 1985).

A rede urbana brasileira era até o início dos anos 1950 assinalada por um grau limitado de diversificação funcional de suas cidades, como Deffontaines (1945) mencionou, a rede urbana brasileira se encontrava em sua "infância", ou seja, seu processo de 
BASTOS, J.M. \& CASARIL, C. Formação sócio-espacial como categoria...

formação havia tão somente iniciado. Sua importância relacionavase a posição que ocupava na hierarquia urbana, vinculada a divisão territorial do trabalho revelada, segundo suas funções centrais distribuídas conforme o modelo hierárquico christalleriano.

Este modelo hierárquico supracitado foi estruturado pelo geógrafo alemão Walter Christaller, nomeando-se "Teoria das Localidades Centrais", elaborada em 1933. Nele, Christaller demonstrou a presença de uma hierarquia "[...] entre cidades determinadas pela lógica da extração tributária e pelas necessidades da circulação mercantil estabelecidas de forma permanente no território. [...]" (IPEA; IBGE; UNICAMP/IE/NESUR, 2002, p.23). Nesta teoria, "[...] qualquer estabelecimento comercial, industrial ou de prestação de serviços, fornece bens e serviços a uma região mais ou menos distante do centro fornecedor, que representa a polarização espacial da aglomeração urbana. [...]" (IPEA; IBGE; UNICAMP/IE/NESUR, 2002, p.26). Proporcionando assim, a constituição de uma hierarquia de cidades, em que, no nível mais elementar, estariam as cidades produtoras basicamente de bens e serviços, aqueles mais procurados pela população para sua reprodução social cotidiana, e, do outro lado, estariam os centros maiores, geradores de produtos e serviços mais especializados para uma área territorial mais extensa.

A respeito da crítica que é realizada aos estudos sobre rede urbana, sobretudo, aquelas pesquisas que se utilizaram do modelo proposto por Christaller, e que foi incorporada por vários autores da chamada Nova Geografia (ou Geografia Quantitativa, Geografia Pragmática ou mesmo, Geografia Teorética) com suas "geometrias estéreis" (para usar a expressão de Corrêa).

É interessante notar que vieram muitas críticas à teoria de Christaller, sendo as mais contundentes, as que declaravam a teoria das localidades centrais serem excessivamente quantitativas, descoladas da realidade e por ai vai, foram produzidas a partir da análise de outros estudos que se utilizaram da teoria e não o estudo proposto por Christaller. Por isso acredita-se que muitos destes estudos exageram sim no quantitativismo, a exemplo de várias publicações realizadas no decorrer dos anos 1970, entre estas, as 
BASTOS, J.M. \& CASARIL, C. Formação sócio-espacial como categoria...

assinadas por Berry \& Horton (1970), Faissol $(1970 ; 1975)$ e por Galvão \& Faissol (1970).

Porém, a teoria de Christaller foi uma formulação pioneira que até os dias atuais é utilizada por vários pesquisadores e institutos de pesquisa. Vale destacar que o próprio Christaller reconhecia certas deficiências de seu sistema, porém, ele nota que:

O esquema matemático rígido [...] desenvolvido é incompleto sob certos aspectos, e sua inexatidão reside mesmo em sua rigidez. Devemos aproximar nosso esquema da realidade; portanto, devemos estudar os fatores que ocasionam mudanças importantes e que devem ser levados em considerações (CHRISTALLER, 1966, p.73).

Assim, o autor reconhece que sua teoria em um determinado momento deve ser modificada, sempre levando em consideração aspectos da realidade analisada, assim, seu esquema rígido é convocado por ele mesmo a ser aperfeiçoado continuamente.

Para Santos (1993, p.53), a rede urbana torna-se "Cada vez mais diferenciada, cada vez mais complexificada, cada cidade e seu campo respondem por relações específicas, próprias às condições novas da realização da vida econômica e social [...] Hoje, cada cidade é diferente da outra, não importa seu tamanho [...]". Essa nova característica da rede urbana, a de ser complexa e diferenciada se expressa, pelas diversas maneiras como ocorrem suas inserções na divisão territorial do trabalho, que podem ser por uma, ou várias produções propriamente ditas. Pois, cada rede e centro urbano se inserem distintamente nos processos de produção, distribuição, circulação e consumo, mesmo porque, no sistema capitalista de produção os centros melhores situados tenderam a se sobressair, visto que, o que interessa é a redução de custos e a elevação de lucros, onde a cada nova atividade surge modelos de localização particulares que buscam atender à lógica do capital.

Conforme mencionado, a posição de um centro na hierarquia não é mais suficiente para entender sua importância. Necessita-se considerar "[...] suas especializações funcionais, sejam industriais 
BASTOS, J.M. \& CASARIL, C. Formação sócio-espacial como categoria...

ou vinculadas aos serviços [...]" porque a “[...] divisão territorial do trabalho entre os centros urbanos amplia-se" (CORRÊA, 1997, p.100). A complexidade funcional oriunda desta nova fase do desenvolvimento econômico-social se traduz no fato de um centro situar-se em pelo menos duas redes. A primeira constituída por localidades centrais, em que cada centro tem sua posição vinculada à distribuição de bens e serviços “'[...] (metrópole, capital regional, centro sub-regional, centro de zona, centro local) [...]”; a segunda, menos desenvolvida e mais irregular, em que cada centro "[...] desempenha um papel singular e/ou complementar a outros centros" (CORRÊA, 1997, p.100).

Assim, cada centro pode ter relações com centros de níveis hierárquicos mais elevados, não necessariamente sendo um centro do próximo nível hierárquico, as relações podem ser realizadas de um centro local diretamente com a metrópole nacional. Conforme a figura 1 percebe-se que o modelo teórico básico não se alterou, o que se alterou foram as múltiplas determinações de suas relações.

Figura 1: Relações entre as cidades em uma rede urbana

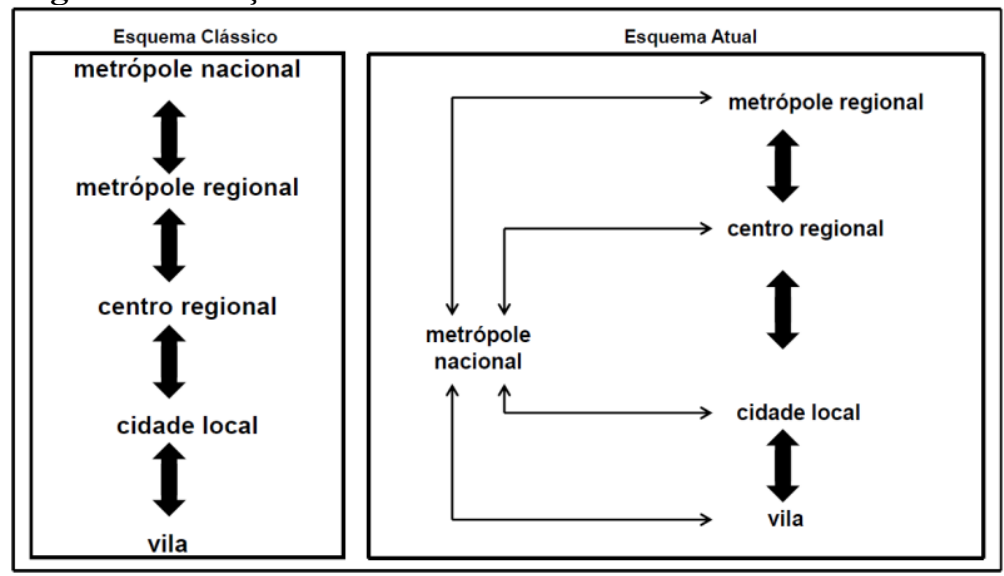

Fonte: Adapt. de SENE e MOREIRA (1999).

Org.: Os autores, 2014. 
BASTOS, J.M. \& CASARIL, C. Formação sócio-espacial como categoria...

Diante disso, a rede urbana brasileira pode ser analisada através da teoria christalleriana, basta fazermos os complementos necessários para acompanhar a complexificação atual da sociedade e rede urbana, visto que a complexidade da DTT leva a numerosas especializações funcionais/produtivas que definem vários centros.

A rede urbana, assim, se relaciona a outras espacialidades, através de uma intensa circulação de mercadorias, pessoas, ideias e informações compondo um conjunto articulado de fixos e fluxos, que ao se interagirem expressam a realidade geográfica, formando o espaço, por meio de "sistemas de objetos" e "sistemas de ações", para utilizar a terminologia de Santos (1985, p. 67), o que é equivalente a "forças produtivas" e "relações de produção" na perspectiva teórica marxista.

Santos (1977, p. 87) lembra que “[...] a localização dos homens, das atividades e das coisas no espaço explica-se tanto pelas necessidades 'externas', aquelas do modo de produção 'puros', quanto pelas necessidades 'internas' [...]”, manifestadas pela "[...] formação social propriamente dita".

O dinamismo exposto pelas necessidades internas e externas acaba refletindo em relações contraditórias que geram conflitos, onde as necessidades externas, como o autor supracitado adverte, são próprias às determinações universais do modo de produção, já os imperativos internos são geridos pelas influências das formações sócio-espaciais, estas determinadas pelos enfoques das elites locais, que concebem subsídios importantes para a explicação e entendimento das especificidades de um dado centro urbano e/ou até mesmo das diferenciações entre os centros urbanos de uma determinada rede urbana.

A partir das ideias do parágrafo anterior, podemos mencionar que, a respeito das elites locais, a realização de um estudo de uma determinada rede urbana, a utilização das ideias de Ignácio Rangel, também é imprescindível, principalmente a nomeada "teoria da dualidade brasileira", momento em que Rangel (1981) expõe a questão dos pactos de poder firmados tanto internamente como externamente em nosso país a cada dualidade, a 
BASTOS, J.M. \& CASARIL, C. Formação sócio-espacial como categoria...

partir desta teoria, pode-se transplantá-la para a cidade e para a rede através da análise dos pactos locais de poder, para mensurarmos quais determinações ocorreram localmente e que foram fundamentais para a reestruturação da rede urbana (CASARIL, 2010; 2014).

A realização de análise de uma dada rede urbana tendo como categoria analítica a formação sócio-espacial é extremamente complexa, necessitando-se, profundas reflexões e investigações empíricas. Além de determinar atenção quanto a cada novo momento da formação sócio-espacial, que permite a apreensão da interpenetração dos contrários.

Portanto, a análise busca a apreensão da realidade, que apresenta múltiplas determinações (MARX, 1987), características próprias de formações sociais antigas e novas (continuidades e descontinuidades), que permitem a interpenetração dos contrários e possibilitam a análise da

[...] especificidade de cada lugar histórica e geograficamente, sem perder de vista o conhecimento do conjunto. Entendida assim, essa visão aponta obrigatoriamente no sentido da interdisciplinaridade indispensável à percepção da totalidade [...]. Como cada região tem também uma parcela de seu desenvolvimento ligado às suas próprias forças, decorrentes de uma trama complexa de elementos, a análise das especificidades de cada formação social ajuda a compreender melhor as determinações que operam sobre os processos responsáveis pela construção das especificidades regionais. Por isso, o método geográfico que tem por base a categoria de formação sócioespacial, proposto por Milton Santos é o que permite a apreensão das especificidades enquanto fruto da combinação de processos distintos. [...] (VIEIRA; PEREIRA, 1997, p. 454, grifo nosso).

Para apreender a dinâmica transformadora de uma determinada rede urbana compete entender a racionalidade da estrutura sócio-espacial, a qual exerce importante função na 
BASTOS, J.M. \& CASARIL, C. Formação sócio-espacial como categoria...

acepção de tornar perceptíveis as lógicas geratrizes (como por exemplo, o latifúndio ou a pequena produção mercantil).

Através do conjunto de noções, ideias, combinações, etc., é que temos que analisar a rede urbana. A complexidade da rede urbana resulta de processos que revelam relações desiguais de trocas, associadas a DTT, que todavia é manifestada por diferentes práticas de atores econômicos, políticos e sociais. Credita-se ao setor produtivo a peça fundamental para se iniciar a análise de qualquer rede urbana, pois se vive numa sociedade capitalista, onde os centros urbanos e por consequência as redes urbanas são estruturadas pela acumulação de capital, através de seus complexos de produção, distribuição, circulação e consumo (CASARIL, 2010; 2014). Valendo enfatizar que, "[...] não apenas a relação de uma nação com outras, porém até mesmo toda a estrutura interna dessa nação, depende do nível de desenvolvimento de sua produção e de seu intercâmbio interno e externo" (MARX; ENGELS, 2007, p. 43). Assim, a partir da análise da produção, edificada no método materialista pode-se explicar teoricamente as relações tanto intraurbanas como inter-urbanas entre os lugares.

Aliás, um fato facilmente observado nos últimos anos, diz respeito ao baixo número de publicações sobre a temática da industrialização, realizadas pela ciência geográfica como um todo. Entretanto, Marx e Engels (1998, p. 21) destacam que,

[...] para viver, é preciso antes de tudo beber, comer, morar, vestir-se e algumas outras coisas mais. $\mathrm{O}$ primeiro fato histórico é, portanto, a produção dos meios que permitem satisfazer essas necessidades, a produção da própria vida material; e isso mesmo constitui um fato histórico, uma condição fundamental de toda a história que se deve, ainda hoje como há milhares de anos, preencher dia a dia, hora a hora, simplesmente para manter os homens com vida.

Portanto, o setor produtivo é fundamental para a vida da humanidade e tal entendimento nos faz constatarmos a importância que as pesquisas relacionadas com esta temática ganha para o 
BASTOS, J.M. \& CASARIL, C. Formação sócio-espacial como categoria...

avanço da ciência geográfica. Destacando que a indústria recebe importância considerável na produção em geral, devido ao seu poder de estimular além do próprio setor industrial, também o setor de comércio e de prestação de serviços, sem esquecer-se que tal setor promove a inserção do capitalismo no campo, ou em outras palavras, a modernização na agricultura. Portanto, o setor industrial é um dos grandes responsáveis pela dinâmica do comércio e dos serviços na economia urbana.

\section{Considerações finais}

Em relação aos estudos sobre redes urbanas, verifica-se que são vários os autores que se dedicam ou se dedicaram as análises desta temática que, não partem da esfera da produção, às vezes até mesmo esquecem tal campo. Desta forma, os mesmos desenvolvem apenas espaciologias estéreis. Assim, os estudos sobre redes urbanas não devem e não podem partir de outra esfera que não seja a da produção, prática essencial já que vivemos em uma sociedade onde impera o capitalismo e, isso contempla os alicerces de nossa proposta, fundamentada na FSE.

Assim, partimos da ideia que temos que utilizar uma perspectiva teórica para analisar uma determinada rede urbana que abarque a totalidade, portanto, não podemos ignorar a formação social como teoria e como método. Sendo assim, a partir destas colocações, é importante destacar que, a proposta teórica mais adequada para a temática abordada é uma perspectiva de grande potencial para análise não só da realidade brasileira, como de outros países e, por que não, das realidades regionais e/ou locais.

Ela foi erigida com base no paradigma de Formação SócioEspacial proposto por Milton Santos no decorrer dos anos 1970, somada à Teoria da Dualidade Básica da Economia Brasileira e seus pactos de poder nomeados pelo professor Ignácio Rangel.

A estas perspectivas teóricas adicionam-se as combinações geográficas de André Cholley (1964a), que, todavia, se soma a proposta das múltiplas determinações de Karl Marx. 
BASTOS, J.M. \& CASARIL, C. Formação sócio-espacial como categoria...

Não podemos deixar de mencionar também que, por trabalharmos com a ideia de formação, estamos sucessivamente realizando nossas análises de maneira a vincular à história, a economia e a geografia, para interpretar uma dada realidade.

Esse texto refere-se a um caminho para entendermos a rede urbana. Sendo imprescindível o estudo dos principais centros, de uma rede, visando encontrar as determinações mais gerais, porque o todo se expressa no local, no singular, através do particular.

Com este artigo entende-se ter avançado no sentido de atingir plenas condições de desmistificar uma dada rede urbana sob o paradigma da formação sócio-espacial, entretanto, sabe-se que sempre se deve aprofundar e que este artigo não esgota com a possibilidade de interpretação da temática.

\section{Referências bibliográficas}

BERNARDES, L.M. C. O Rio de Janeiro e sua Região. Rio de Janeiro: IBGE/CNG, 1964.

BERRY; HORTON, F.E. Geographic perspectives on urban systems. Englewood Cliffs: Prentice-Hall, 1970.

BESSA, K. A dinâmica da rede urbana no Triângulo Mineiro: Convergências e Divergências entre Uberaba e Uberlândia. Uberlândia: [s.n.], 2007.

BONFIM, P.R. de A. XVIII Congresso Internacional da UGI, Rio de Janeiro, 1956. Anais ... XVI Encontro Nacional dos Geógrafos. Porto Alegre, 2010, p.01-07.

CASARIL, C.C. Meio século de verticalização urbana em Londrina - PR e sua distribuição espacial: 1950-2000. 2008. Dissertação (Mestrado Geografia) PPGG-UEL, Londrina, 2008. 
BASTOS, J.M. \& CASARIL, C. Formação sócio-espacial como categoria...

. "Pequenas Cidades" ou "Cidades Locais"? Por uma perspectiva teórico-metodológica atual. Anais... XVI Encontro Nacional dos Geógrafos. Porto Alegre, 2010, p.1-13.

. A dinâmica da rede urbana de Francisco Beltrão Paraná. 2014. Tese (Doutorado em Geografia) PPGGEO - UFSC, Florianópolis, 2014.

CHOLLEY, A. Observações sobre alguns pontos de vista geográficos (part. 1). Boletim Geográfico. Rio de Janeiro: IBGE, n.179, p. 139-145. 1964a.

. Observações sobre alguns pontos de vista geográficos (part. 2). Boletim Geográfico. RJ: IBGE, n.180, p.267-276. $1964 b$.

CHRISTALLER, W. Central Places in Southern Germany. Prentice-Hall, Inc. Englewood Cliffs, 1966.

CORRÊA, R.L. Os estudos de redes urbanas no Brasil. Revista Brasileira de Geografia, Rio de Janeiro, v. 29, n. 4, p. 93-116, out./dez. 1967.

- A rede de localidades centrais nos países subdesenvolvidos. Revista Brasileira de Geografia, Rio de Janeiro, v. 50, n. 1, p. 61-83, jan./mar. 1988.

. A rede urbana. São Paulo: Ática, 1989.

. Trajetórias geográficas. RJ: Bertrand Brasil, 1997.

. Estudos sobre a rede urbana. Rio de Janeiro: Bertrand Brasil, 2006. 336p.

DEFFONTAINES, P. Como se constituiu no Brasil a Rede das Cidades. Boletim Geográfico, v.2, n. 14, p. 141-148, maio, 1944. 
BASTOS, J.M. \& CASARIL, C. Formação sócio-espacial como categoria... . Como se constituiu no Brasil a Rede das Cidades II. Boletim Geográfico, v.2, n. 15, p. 299-308, maio, 1945.

ESPÍNDOLA, C.J.; SILVA, M.A. da. Formação Sócio-Espacial: um referencial aos estudos sobre industrialização (notas). Experimental, São Paulo, n. 3, p. 61-67, setembro, 1997.

FAISSOL, S. As grandes cidades brasileiras: dimensões básicas de diferenciação e relação com o desenvolvimento econômico. Um estudo de análise fatorial. Revista Brasileira de Geografia, Rio de Janeiro, v. 32, n. 4, p. 87-130, 1970.

- Urbanização e regionalização: relações com o desenvolvimento econômico. Rio de Janeiro: IBGE, 1975.

FERREIRA, S.C. A formação socioespacial como orientação teórico-metodológica no estudo da rede urbana regional. Caminhos de Geografia. Uberlândia. V.12, n.37, p.1-7, março, 2011.

FRESCA, T.M. A dinâmica funcional da rede urbana do oeste paulista. 1990. Dissertação (Mestrado em Geografia) PPGG, UFSC, Florianópolis.

. Transformações da rede urbana do Norte do Paraná: estudo comparativo de três centros. 2000. Tese. (Doutorado em Geografia Humana) Faculdade de Filosofia, Letras e Ciências Humanas, Universidade de São Paulo, São Paulo.

2004.

. A rede urbana do norte do Paraná. Londrina: Eduel,

GALVÃO, M.V.; FAISSOL, S. A Revolução quantitativa na Geografia e seus reflexos no Brasil. Revista Brasileira de Geografia, Rio de Janeiro, v. 32, n. 4, p. 05-22, 1970. 
BASTOS, J.M. \& CASARIL, C. Formação sócio-espacial como categoria...

GEIGER, P.P. Evolução da rede urbana brasileira. Rio de Janeiro: Centro Brasileiro de Pesquisas Educacionais, 1963.

IBGE, Instituto Brasileiro de Geografia e Estatística. Esboço preliminar de divisão do Brasil em espaços homogêneos e espaços polarizados. Rio de Janeiro, 1967.

. Subsídios à Regionalização. RJ: IBGE, 1968.

. Divisão do Brasil em regiões funcionais urbanas. Rio de Janeiro, 1972. 110p.

. Regiões de influência das cidades brasileiras. Rio de Janeiro, 1987.

. Regiões de influência das cidades 1993. Rio de Janeiro: IBGE, 2000. 230p.

. Regiões de influência das cidades 2007. Rio de Janeiro: IBGE, 2008. 201p.

IPARDES. Instituto Paranaense de Desenvolvimento Econômico e Social. Crescimento, reestruturação e competitividade industrial no Paraná: 1985-2000. Curitiba: IPARDES, 2002.

Leituras regionais: mesorregiões geográficas paranaenses. Curitiba, 2004.

IPEA; IBGE; UNICAMP/IE/NESUR. Caracterização e tendências da rede urbana do Brasil: Redes urbanas regionais: Norte, Nordeste e Centro-Oeste. Brasília: IPEA, 2002. v.4.

KOSIK, K. A dialética do concreto. RJ: Paz e Terra, 1976. 
BASTOS, J.M. \& CASARIL, C. Formação sócio-espacial como categoria...

LÊNIN, V.I. O desenvolvimento do capitalismo na Rússia: o processo de formação do mercado interno para a grande indústria. São Paulo: 1982.

LOSCH, A. The economics of location. New Haven: Yale University Press, 1954.

MAMIGONIAN, A. A Geografia e "A Formação Social como Teoria e como Método". In: SOUZA, M. A. A. de. (Org.) Mundo do cidadão, um cidadão do mundo. São Paulo: Hucitec, 1996, p.198-206.

MARX, K. O capital. São Paulo: Abril Cultural, 1983. v. 1.

. Contribuição à crítica da economia política. São Paulo: Martins Fontes, 1987.

; ENGELS, F. A ideologia alemã. São Paulo: Martins Fontes, 1998.

- A ideologia Alemã: Crítica da novíssima filosofia alemã em seus representantes Feuerbach, B. Bauer e Stirner, e do socialismo alemão em seus diferentes profetas, 1845-1846. Trad. Marcelo Backes. Rio de Janeiro: Civilização Brasileira, 2007.

MONBEIG, P. O estudo geográfico das cidades. Boletim Geográfico, a.1, n. 7, p. 7-29, maio, 1943.

. Pionners et Planteurs de São Paulo. Paris: Librairie Armand Colin, 1952.

. Resumo da Geografia Econômica do café. Boletim Geográfico, a.12, n. 122, p.276-287, set./out., 1954. 
BASTOS, J.M. \& CASARIL, C. Formação sócio-espacial como categoria...

MÜLLER, N.L. Evolução e estado atual dos estudos de geografia urbana no Brasil. Boletim Geográfico, Rio de Janeiro, n. 209, p. 28-64, mar./abr. 1969.

PERROUX, F. O conceito de pólo de crescimento. In: FAISSOL, S. (Org.). Urbanização e regionalização, relações com o desenvolvimento econômico. RJ: IBGE, 1978. p.97-110.

RANGEL, I. A história da dualidade brasileira. Revista de Economia Política, São Paulo, v. 1, n. 4, p. 5-34, out./dez., 1981.

RIBEIRO, M.A.C. A complexidade da rede urbana amazônica: três dimensões de análise. RJ, 1998. Tese (Doutorado). UFRJ.

ROCHEFORT M. Determination des types de villes d'un reseau urbain - méthode d'analyse de la population active. In UGI. Union Géographique Internationale. Les comptes rendus du XVIIIe Congrès International de Géographie. Rio de Janeiro: UGI, Comité du Brésil, 1959, III, p.426-431.

- Métodos de estudos das redes urbanas: interesse da análise e do setor terciário da população ativa. Boletim Geográfico, a. 19, n. 160, p. 3-19, jan./fev., 1961.

SANTOS, M. Sociedade e Espaço: A Formação Social como Teoria e como Método. Boletim Paulista de Geografia, São Paulo, n.54, p.81-100, jun. 1977.

O espaço dividido: os dois circuitos da economia urbana dos países subdesenvolvidos. RJ: F. Alves, 1979.

. Espaço e método. São Paulo: Nobel, 1985.

. A urbanização brasileira. São Paulo: Hucitec, 1993. 
BASTOS, J.M. \& CASARIL, C. Formação sócio-espacial como categoria...

SENE, E. de; MOREIRA, J. C. Geografia Geral e do Brasil. São Paulo: Scipione, 1999.

SERENI, E. De Marx a Lenin: la categoria de "formación económica - social". Economia y Ciencias Sociales, Caracas, v. 13, p. 5-53, 1971.

UGI (Union Géographique Internationale). Les comptes rendus du XVIIIe Congrès International de Géographie. Rio de Janeiro: UGI, Comité du Brésil, 1959. <http://www.iguonline.org/site/>.

VIEIRA, M.G.E. de D.; PEREIRA, R.F. do A. Formações SócioEspaciais Catarinenses: nota preliminar. Anais... Congresso de História e Geografia de SC. Florianópolis: CAPES, 1997, p. 453463.

Recebido em junho de 2016 Aceito em agosto de 2016 